\title{
Free energy landscapes and residue network analysis for six SARS-CoV-2 targets in complex with plausible phytochemical inhibitors from Withania somnifera: $1 \mu$ s molecular dynamics simulations
}

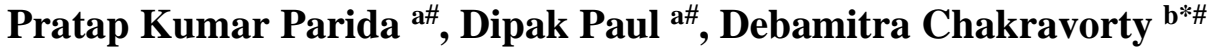

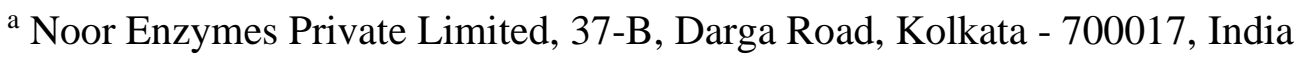 \\ b Novel Techsciences (OPC) Private Limited, 37-B, Darga Road, 1st Floor, Kolkata- 700017, \\ India \\ * Corresponding author: \\ Debamitra Chakravorty, PhD (Project Lead - Computational Biology) \\ Novel Techsciences (OPC) Private Limited, 37-B, Darga Road, 1st Floor, Kolkata- 700017, \\ India. \\ E-mail: dc@noveltechsciences.com \\ \#All the authors have contributed equally to the paper.
}

\begin{abstract}
The pandemic is here to stay- evident from the second wave that is severely affecting global population. Though vaccination is now available, the population size restricts its efficacy, especially in the third world countries. Therefore, to avoid a third wave, natural preventive therapeutics are the need of the hour. In this work the efficiency of phytochemicals from Withania somnifera to bind to a total of six SARS-CoV-2 targets have been shown. $1 \mu \mathrm{s}$ molecular dynamics simulations and essential dynamic analyses shed light on the changes induced by the phytochemicals and highlights their multipotent capabilities- 27 Hydroxywithanolide B was able to bind to three targets. Relative free energy of binding for all the phytochemicals were calculated by MM/PBSA. Minimum energy structures were extracted from their free energy landscapes and were subjected to PSN-ENM-NMA and network centrality analysis. Results showed that the phytochemical binding changes the residue-residue interaction network. Network communities increase while hubs and links decrease. Metapath rewiring occurs through residues Phe456 in spike protein, Thr26 and Tyr118 in main protease, Val49 and Phe156 in NSP3, Leu98 in NSP9, Leu4345 in NSP10, Phe440 and Phe843 in NSP12. This work tries to understand the mechanism of possible inhibition by the phytochemicals to combat SARS-CoV-2 with their capability of targeting multiple proteins. The insight from this study can be of great relevance to explore the changes in network properties induced by reported potential inhibitors against SARS-CoV-2 targets.
\end{abstract}

Keywords: SARS-CoV-2, targets, phytochemicals, MD simulations, protein residue network. 


\section{Introduction}

The average cost to develop a new drug is almost 2.6 billion U.S. dollars involving 612 years (DiMasi et al., 2016), bulk of which goes into accessing drug safety. Acceleration of this process is required in the case of the COVID-19 pandemic which is caused by SARS-CoV2 and is associated with substantial morbidity and mortality rates. The cure to the infection is yet to reach global market. The resurgence in COVID-19 cases as part of the second wave has been observed globally. Additional concern is that neutralizing antibody mediated immunity related to SARS-CoV-2 is weak and starts to decrease after 2-3 months (Long et al., 2020). It has also been reported that asymptomatic or minimally symptomatic patients can spread the virus efficiently and it is difficult to clinically identify them without bulk testing (Long et al., 2020). This has led to failure to contain the pandemic (Bai et al., 2020) and warrants the development of prophylactic measures to combat the viral infection by strengthening immunity against the virus. In this context, in silico research has progressed to identify potential chemical inhibitors and many such research report natural compounds for screening purposes to be effective against SARS-CoV-2 (Chen et al., 2020; Jin et al., 2020; Luo et al., 2020; Pang et al., 2020; Parida et al., 2020; Xu et al., 2020; Yang et al., 2020; Zhang et al., 2020). The SARS$\mathrm{CoV}-2$ virus primary transmission occurs due the priming of the heterotrimeric Spike protein S1 subunit with the ACE2 (angiotensin-converting enzyme 2) cellular receptor (Chen et al., 2020; Tian et al., 2020). The main protease is another important target as it is vividly involved in viral replication process (Huynh et al., 2020; Joshi et al., 2020). The other important targets, partaking in viral replication, are 4 non-structural proteins (NSPs). The targeted NSPs were NSP3, NSP9, NSP10, and NSP12. NSP3 is papain-like proteinase, NSP9 is the RNA-binding protein as it is thought to mediate viral replication, NSP10 is a cofactor for the activation of the replicative enzyme in SARS-CoV, NSP16 is a 2'-O-ribose-methyltransferase in SARSCoV-2. NSP12 is the RNA-dependent RNA polymerase in SARS-CoV-2. Important sites in NSP12 that can be targeted by drugs are site D1 which is the active site of the polymerase and site D2 which is the NSP7 priming site. NSP7 and NSP8 are co-factors that stimulate polymerase activity (Subissi et al., 2014).

Interestingly in our earlier, work by performing $100 \mathrm{~ns}$ classical molecular dynamics simulations of virtually screened phytocompounds, we realized that Withania somnifera compounds were with the lowest relative free energy of binding with these targets (Parida et al., 2020; Parida et al., 2021). Withanolides have been reported to possess diverse biological functions, for example anti-inflammatory (Kaileh et al., 2007), immunomodulatory (Malik et 
al., 2007), anti-angiogenesis (Mohan et al., 2004), and anticancer activities (Yang et al., 2007). They have also been reported to reduce markers of inflammation (including IL-1 and TNF- $\alpha$ ) in vivo (Howes \& Houghton, 2009). A total 30 clinical studies documented the safety and efficacy of Withania somnifera (Tandon \& Yadav., 2020). Further, withanolides from Withania somnifera, showed anti-viral activity for Human Papilloma Virus, influenza viruses, herpes simplex virus, sindbis virus, parainfuenze-3 virus, human cytomegalovirus, and dengue virus type-2 (Amoros et al., 1994; Cai et al., 2015; Kwon et al., 2020; Latheef et al., 2017; Lyu et al., 2005; Munagala et al., 2011; Serkedjieva et al., 1992; Zandi et al., 2011). Withanone from Withania somnifera was also observed to interact with main protease (Mpro) and spike protein of SARS-CoV-2 (Kumar et al., 2020; Tripathi et al., 2020; Balkrishna et al., 2021).

In this context and the knowledge that major conformational changes occur on timescales ranging from micro- seconds to seconds (Klepeis et al., 2009), through this work, we describe our efforts in establishing the interaction dynamics of important residues in SARSCoV-2 targets upon binding to these phytochemicals by performing 1 micro-second simulations. Essential dynamics analysis, free energy landscapes and residue interaction networks (PSN-ENM-NMA) were analysed in these complexes and compared to the free proteins for understanding the mechanism of inhibition induced by these phytochemicals. Residue interaction networks, graph theoretically, convert a protein's residues to nodes and links (Di Paola et al., 2013). Based on this an impressive tool- Protein Structure Network (PSN) and Elastic Network Model-Normal Mode Analysis (ENM-NMA) based strategy was developed to study residue communication network in biomolecules (Felline et al., 2020). By this method differences in nodes, links, communication pathways, and metapaths were computed for the six SARS-CoV-2 targets in free and in complex with the phytochemicals. The differences obtained in residue network were correlated to the effect the phytochemicals can have in residue communication that define the correct functioning of the phytochemical free targets. As a protein's function and stability, rely on complex network of inter-residue interactions, the all-atom weighted network centrality measures (degree, betweenness and interaction strength) were computed for each of the six targets (Chakrabarty \& Parekh, 2016). The difference in the centrality measures defined the changes in residue interaction network brought about by the bound phytochemicals. 


\section{Methods}

\section{All atom explicit solvent Molecular dynamics simulations}

High Performance Computing resources of Amazon EC2 G4 instances were employed for carrying out computational work with the help of RONIN interface- Amazon web service research platform (https://ronin.cloud/) as an award granted by the COVID-19 High Performance Computing (HPC) Consortium for carrying out this work (https://covid19-hpcconsortium.org/projects).

A total of six SARS-CoV-2 and phytochemical docked complexes (main protease, spike protein, NSP3, NSP9, NSP10 and NSP12) were analysed by all atom molecular dynamics (MD) simulations. For ease of paper drafting and understanding, NSP3, NSP9, NSP10 and NSP12 will be referred as other targets in the following sections. The complexes were obtained from our previous work (Parida et al., 2021). All the simulations were carried out with Gromacs 2020.2 software package (Lindahl et al., 2020) with AMBER99SB-ILDN force field for all atoms were chosen to run MD simulation. Complex charges were neutralized with sodium and chloride ions. Simulation was conducted at $300 \mathrm{~K}$ under a pressure of 1 bar. Each system was minimized with 5,000 steps by steepest descent algorithm. Electrostatic interactions were calculated with Particle-Mesh-Ewald summation (PME) (Darden et al., 1993). The systems were equilibrated by $1 \mathrm{~ns}$ position restraint simulations of $1000 \mathrm{~kJ} \mathrm{~mol}^{-1} \mathrm{~nm}^{-2}$ in the NVT and NPT ensembles. Equilibrated systems were used to simulate a $1 \mu$ s no restraint production run.

\section{Trajectory analysis}

Post-MD analyses included root mean square deviation (RMSD), root mean square fluctuations (RMSF) and the radius of gyration (Rg). RMSD and RMSF stabilities are essential to obtain good binding affinities (Doniach \& Eastman, 1999; Chen \& Shen, 2009; Dubey et al., 2013). Further, Principal component (PCA) and dynamic cross correlation (DCCM) analysis were performed. Essential dynamics allows the understanding of dominant and collective modes from the overall dynamics of the MD trajectory. To perform PCA, covariance matrices were constructed by calculating the eigenvectors and eigenvalues and their projection along with the first two principal components (PCs) were analysed. Principal component analysis (PCA) of the $\mathrm{C} \alpha$ Cartesian coordinates reflects overall difference in motions in the protein on binding ligands in comparison to the free-protein (Martens \& Naes 1992; Islam et al., 2019). Like PCA, correlation in the protein residue atomic motions can be mapped with the help of Dynamic Cross Correlation Matrix (McCammon, 1984; Hünenberger et al., 1995). PCA and DCCM calculations were performed using Rstudio (RStudio Team, 2020) and Bio3d 
(Grant et al., 2006). Additionally, Molecular Mechanics - Poisson Boltzmann Surface Area (MM-PBSA) was applied on snapshots obtained from MD trajectory to estimate the relative binding free energy using the GROMACS tool g_mmpbsa (Baker et al., 2001; Kumari et al., 2014).

\section{Free Energy Landscapes and residue interaction network analysis}

The Free Energy landscape (FEL) was constructed from PC1 and PC2 projections using g_sham tool in GROMACS MD package. The global minimum conformations were extracted from the FEL bins. These structures acted as representatives for atom pair weighted network centrality measures, which was performed using the NAPS webserver (Chakrabarty \& Parekh, 2016). High centrality measures correlate to a node's capacity to effect protein function. This analysis was performed to understand if the centrality measures of the essential residues in the SARS-CoV-2 targets change upon binding to the phytochemical inhibitors. This will affect the communication network required for the proper functioning of the proteins. The centrality measures were normalized between 0-1, by min-max scaling, to perform comparative analysis between the phytochemical free and bound form- minimum energy structures. The formula used has been represented below. In Eq 1, x represents the centrality measure; $\min (\mathrm{x})$ is the minimum value and $\max (\mathrm{x})$ is the maximum value.

$$
\text { Scale }(0-1)=\frac{x-(\min (x))}{(\max (x)-\min (x))}
$$

The residues with values close to 1 were considered important for protein function and the difference in the centrality measures were correlated to the effect of phytochemical binding. The various centrality measures analysed in this work were:

Degree centrality: This represents a highly connected amino acid residue (node) in a protein structure. High degree node is important for structural stability and information flow in a protein structure (Amitai et al., 2004; del Sol et al., 2006).

Betweenness centrality: This indicates how central an edge between two residues is to the various communication pathways in a network (Amitai et al. 2004). A node with high betweenness, indicates that it is central to mediate interactions with other nodes. Thus, it may be of functional importance (Hu et al., 2014). 
Interaction strength: Number of non-bonded interactions between two residues is captured in interaction strength values for an amino acid residue. Higher value is representative of higher strength (Chakrabarty \& Parekh, 2016).

\section{Structure Network (PSN) and Elastic Network Model-Normal Mode Analysis (ENM-NMA)} webPSN v2.0 was used to build protein structure networks for the six SARS-CoV-2 free protein targets and in complex with the phytochemicals (Felline et al., 2020). The tool uses pairwise interaction energies to build the networks and cross-correlation of atomic motions is supplied by ENM-NM (Felline et al., 2020). The structures obtained from minimum energy bins in their FEL were used to construct the network. The network properties analysed were nodes, links, hubs, communities, shortest and longest paths, and global communication metapath.

Nodes and Links: The amino acid residues in the protein form the nodes of the network graph and they are connected by edges based on the non-covalent interaction strength between residues and highly interconnected nodes form links (Felline et al., 2020).

Hubs: Hubs represent highly connected residues (4 or more connections) in the protein structure network. The hubs are involved in maintaining structural stability and information flow in the protein structure network (Amitai et al., 2004; del Sol et al., 2006).

Community: They are subgraphs in a network where residues are highly connected, with no connection with residues outside the community (Palla et al., 2005, Felline et al., 2020).

Shortest path: Shortest communication paths are searched by Dijkstra's algorithm (Felline et al., 2020). They represent allosteric signalling among the residues belonging to the shortest path (Ghosh \& Vishveshwara, 2007).

Metapath: Represents a global picture of the structural wiring due to residue communication (Felline et al., 2020).

\section{Results and Discussions}

MD simulation and Residue Interaction Network (RIN) analysis of Spike protein and its complex with 2,3-Dihydrowithaferin A

The spike protein of SARS-CoV-2 docks human angiotensin-converting enzyme 2 (ACE2), mediating viral cell entry (Huang et al., 2020). The $\mathrm{S} 1$ subunit and the S2 subunit are responsible for viral fusion. The receptor binding domain lies in the $S 1$ subunit. The residues interacting with human ACE2 receptor are residues 436-506 (PDB ID: 6lzg) (Lan et al. 2020). 
Leu455, Phe456, Tyr473, Ala475, and Tyr489 form hydrophobic contacts and residues 498 to 505 form hydrogen bonding network with ACE2 receptor (Wang et al., 2020). The compound 2,3-Dihydrowithaferin A was found to dock to the RBD region. This complex was subjected to MD simulation and protein structure network and centrality analysis.

\section{Trajectory analysis and study of essential dynamics}

First, $\mathrm{C} \alpha$ atoms root mean-square deviations (RMSD) of from the initial conformer were computed to find the overall stability and convergence of simulations. All the trajectories were stable as $\mathrm{C} \alpha \mathrm{RMSD}$ were observed to converge over the $1 \mu$ s trajectories (Figure 1A). Secondly, the Ca RMSF of the complex was computed to be higher than the free protein (Figure $1 \mathrm{~B}$ ). In PCA the phytochemical complex (SP) was observed to explore much more conformational space than the free (SA) (Figure 1D, E). Analysis of difference in residue fluctuation in PC1 for SP - SA, showed that upon ligand binding fluctuations increased in the RBD (ACE2 receptor interacting region) of the spike protein (Figure 1F). DCCM analysis showed that both correlation and anti-correlation increased upon phytochemical binding at the RBD region (Figure 1E). Thus, it can be said that phytochemical binding results in higher fluctuations in the RBD of the spike protein.

(A)

(B)
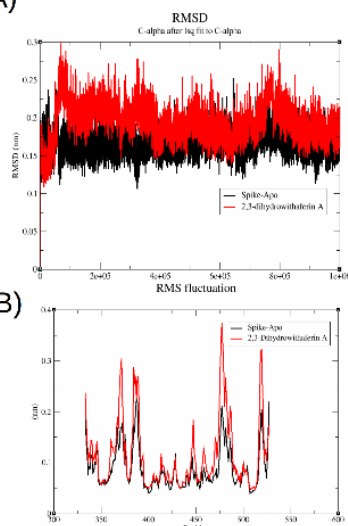

(F)

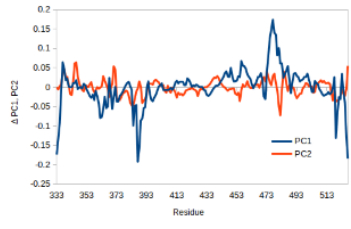

(D)
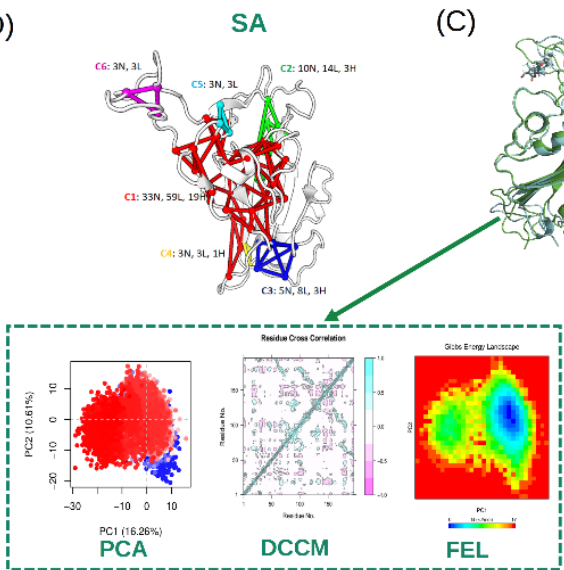

(G)

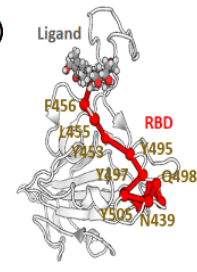

(C)

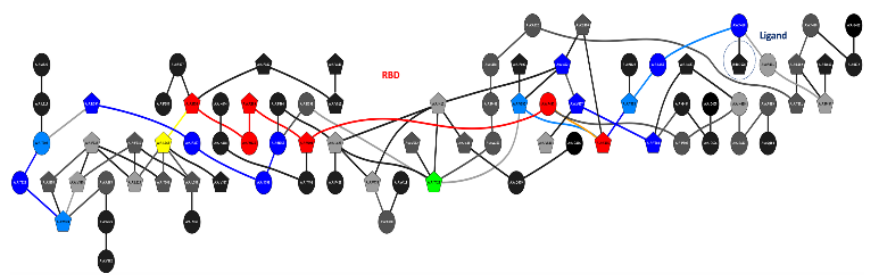


Figure 1: Trajectory and PSN-ENM-NMA analysis of spike protein in free form (SA) and in complex with the phytochemical (SP). A) C $\alpha$ RMSD, B) C $\alpha$ RMSF (Red: SP, Black SA). C) Superimposed minimum energy structure obtained from FEL computed from PC1 and PC2 eigenvectors. D) Community network of SA (green): 6 communities are observed. PCA, DCCM and FEL plots of SA are represented inside the green box. E) Community network of SP (cyan): 7 communities are observed. PCA, DCCM and FEL plots of SA are represented inside the cyan box. F) Difference in residue fluctuation over PC1 and PC2 space between SP-

SA. Positive values represent increased fluctuations in SP. G) Metapath of SP. Relative recurrence average interaction strength of their links: Black $<$ Blue $<$ Green $<$ Yellow $<$ Red. The ligand and RBD is marked in Figure. The residues in the metapath of phytochemical have also been labelled.

\section{Free energy landscapes, network centrality analysis, Structure Network (PSN) and Elastic}

\section{Network Model-Normal Mode Analysis (ENM-NMA)}

Analysis of the FEL contour maps, constructed using the projections of first (PC1) and second (PC2) eigenvectors, showed that SA and SP formed different energy clusters (Figure 1D, E). The conformations found in the blue area are more stable than the red area. FEL revealed $\Delta \mathrm{G}$ value 0 to 17 and $17.6 \mathrm{~kJ} / \mathrm{mol}$ for $\mathrm{SA}$ and $\mathrm{SP}$ respectively. The global minimum energy conformations were obtained from FEL bins and superimposed (Figure $1 \mathrm{C}$ ). These conformations were then subjected to network centrality analysis, Structure Network (PSN) and Elastic Network Model-Normal Mode Analysis (ENM-NMA). Figure 1 D, E shows the residue community formed in the SA (green) and SP (cyan). The number of communities in spike protein increased upon phytochemical binding (SA: 6 communities, SP: 7 communities). Increase in community can imply difference in interacting pathways due to phytochemical binding. Similar trends of ligand induced changes were previously reported by Bhattacharyya \& Vishveshwara (2010). The community architecture was also observed to change upon phytochemical binding -evident from the differences in the number of nodes, hubs and links that define a community (Figure 1D, E, Supplementary Table 1, 2). Increase in number of communities upon ligand binding have been reported earlier (Ghosh \& Vishveshwara, 2008).

Metapath analysis upon ligand binding showed that the ligand formed allosteric communications, with high recurrence (90-100\%), with the RBD binding region (Figure 1G). A total of 72 interactions were lost and 92 new interactions formed in SP. The total number of shared interactions were 164. Among the lost interactions, the loss of Asn334-Val362 was with the maximum paths force (interaction strength with $\mathrm{I}_{\min }$ cutoff 7.27 for SA and 6.29 for SP). $I_{\min }$ represents the lowest interaction strength needed to link two nodes (Felline et al. 2020). Among the shared interactions, the reduction in path force was remarkable for Val341-Val511. Among the new interactions formed the interaction with maximum path force was for Ile434- 
Tyr369. Phe456 was with the maximum paths force with the phytochemical followed by Tyr473 (Supplementary Data 2, Table 1).

Further analysis of pathway recurrence was performed. Recurrence value represents the relative recurrence of nodes and links in the path pool (Felline et al., 2020). The high recurrence value obtained for the phytochemical implies that phytochemical binding can affect the interactions required in the RBD region, to bind to human ACE2 receptor. It can be said here that Phe486, Tyr505, Asn501, Tyr489, Gln493, Leu455 were reported to form strong interactions with the ACE2 receptor (Behloul et al., 2021). Therefore, disruption of allosteric interactions of these residues upon phytochemical binding can result in its inhibition to bind to ACE2 receptor. From PSN-ENM-NMA analysis it was observed that the number of intraresidue interactions for Phe486, Asn501, Tyr505 increases in phytochemical complex compared to the free protein. It was also observed that residue Tyr489 formed 10 times stronger interaction with Thr500 in SA, this interaction was absent in SP. However, in the SP, Tyr498 formed stronger interactions with residues Gly446, Gly447 and Asn501. Phe456 and Tyr489 also formed interactions with phytochemical. Tyr505-Arg403 interaction was stronger in SA whereasTyr505-Asn501 was stronger in SP. Tyr449 and Asn450 interaction formed in SP whereas its interaction with Gly447 and Gly496, observed in SA was absent in the SP. This shows disruption of long-range interactions, required for binding of the spike protein with the ACE2 receptor, upon phytochemical binding. Interaction strength of residue Gln493 with Leu455 increases in SP. Thus, disruption of its allosteric communication network upon phytochemical binding can result in inhibition of its binding to the ACE2 receptor.

Conclusively it can be said that residue interaction path, nodes, communities, hubs, and long-range interactions, especially in the RBD region, changes upon phytochemical binding, this may result in interruption of the spike protein interaction with the ACE2 receptor.

\section{MD simulation and Residue Interaction Network (RIN) analysis of main protease and its complex with Withanolide $R$}

This main protease is required for proteolytic processing of polyproteins (Estrada, 2020; Morse et al., 2020). The 3D structure of main protease can be divided into Domain I (residues 8-101), domain II (residues 102-184) and domain III (residues 201-306) and the active site is in between domain I and II (His41-Cys145 as catalytic dyad, Cys145, Gly143, Ser144, His163, Glu166 and Gln189). A loop (residues 185-200) connects domain II and domain III (Wu et al., 2020). The free form and the docked complex of Withanolide R with main protease was subjected to MD simulation and protein structure network analysis. 


\section{Trajectory analysis and study of essential dynamics}

Initially root mean-square deviation (RMSD) $\mathrm{C} \alpha$ atoms from the main protease free form and in complex with Withanolide R (PA and PP respectively) from the initial conformer were computed- to find the overall stability and convergence of simulations. All the trajectories were stable as $\mathrm{C} \alpha \mathrm{RMSD}$ were observed to converge over the $1 \mu$ s trajectories (Figure $2 \mathrm{~A}$ ). The $\mathrm{C} \alpha$ RMSD of PP was found to be lower than PA (Figure 2A). This indicates that the complex of main protease with the phytochemical was more stable than the free protein. Analysis of C $\alpha$ RMSF showed that PP had lower residue fluctuations than PA (Figure 2 B). Analysis of the $2 \mathrm{D}$ projection of $\mathrm{PC} 1$ and $\mathrm{PC} 2$ showed that PA explored much more conformational space than the PP (Figure 2D, E). Analysis of difference in residue fluctuation in PC1 and PC2 for PP - PA, showed that upon ligand binding fluctuations increased in PC1 but decrease in fluctuations were observed in PC2 especially around Met165 (Figure 2F). DCCM analysis showed that both correlation and anti-correlation increased upon phytochemical binding (Figure 2E). Thus, it can be said that phytochemical binding results in lower fluctuations in the main protease and results in higher conformational stability.

(A)

(D)

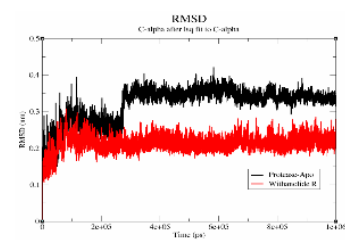

(B)

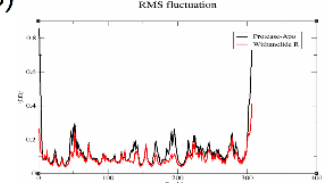

$(\mathrm{F})$
PA

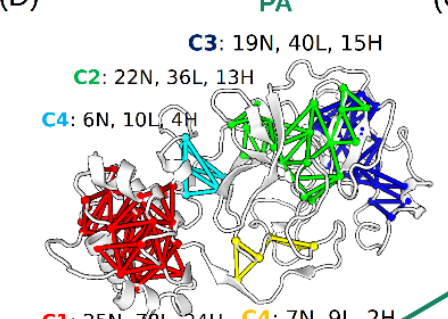

(C)

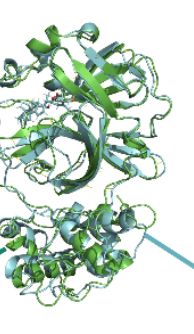

(E) $\quad \mathrm{PP}$

C3: $14 \mathrm{~N}, 24 \mathrm{~L}, 8 \mathrm{H} \mathrm{F} 2: 19 \mathrm{~N}, 40 \mathrm{~L}, 16 \mathrm{H}$

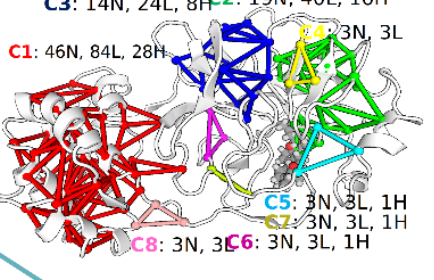

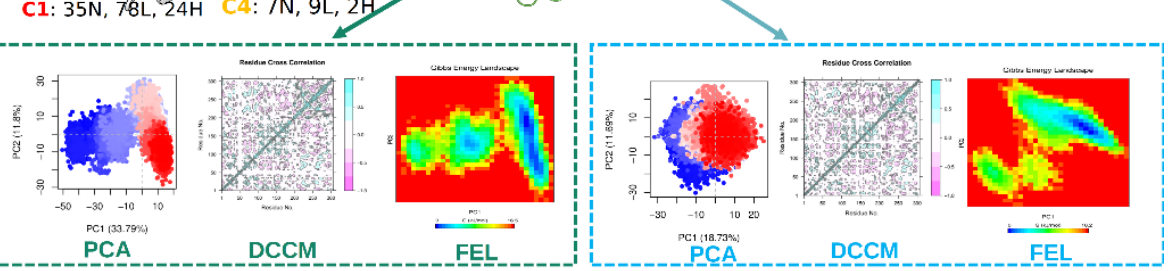
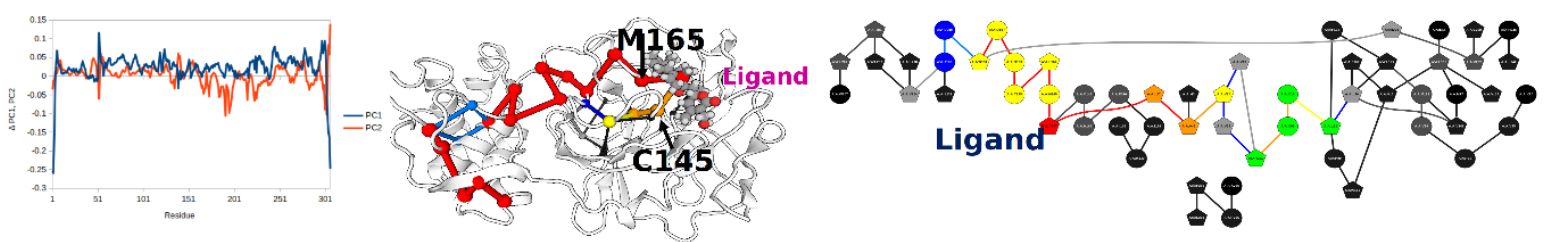

Figure 2: Trajectory and PSN-ENM-NMA analysis of main protease (NSP5) in free form (PA) and in complex with the phytochemical (PP). A) C $\alpha$ RMSD, B) C $\alpha$ RMSF (Red: PP, Black PA). C) Superimposed minimum energy structure obtained from FEL computed from PC1 and PC2 eigenvectors. D) Community network of PA (green): 5 communities are observed. PCA, 
DCCM and FEL plots of PA are represented inside the green box. E) Community network of PP (cyan): 8 communities are observed. PCA, DCCM and FEL plots of PA are represented inside the cyan box. F) Difference in residue fluctuation over PC1 and PC2 space between PPPA. Positive values represent increased fluctuations in PP. G) Metapath of PP. Relative recurrence average interaction strength of their links: Black $<$ Blue $<$ Green $<$ Yellow $<$ Red.The ligand is marked in Figure. Two residues in the active site have been labelled.

\section{Free energy landscapes, Structure Network (PSN) and Elastic Network Model-Normal}

\section{Mode Analysis (ENM-NMA)}

Analysis of the FEL contour maps, constructed using 2D projections of PC1 and PC2 eigenvectors, showed that PA and PP formed different energy clusters (Figure 2D, E). The conformations found in the blue area are more stable than the red area. FEL revealed $\Delta \mathrm{G}$ value 0 to 16.5 and $18.2 \mathrm{~kJ} / \mathrm{mol}$ for $\mathrm{PA}$ and $\mathrm{PP}$ respectively. The global minimum energy conformations were obtained from FEL bins and superimposed (Figure $2 \mathrm{C}$ ).

The global energy minimum conformation obtained from FEL bin were subjected to network centrality analysis, protein structure network (PSN) and elastic network model-normal mode analysis (ENM-NMA). Figure 2 D, E shows the residue community formed in the PA (green) and PP (cyan). The number of communities in main protease increased upon phytochemical binding (PA: 5 communities, PP: 8 communities). Most of the community changes occur in domain I, II and the loop that connects domain II and III. Increase in community can imply functional communication among residues get rewired, due to phytochemical binding. The community architecture was rewired as evident from the changes in the number of nodes, hubs and links that define a community (Figure 2D, E, Supplementary Table 3,4). A total of 144 interactions were lost and 135 new interactions formed upon phytochemical binding. The total number of shared interactions were 245 (Supplementary material 2 Table 2).

Metapath analysis upon ligand binding showed that the ligand formed allosteric communication with high recurrence (90-100\%), with the catalytic site (Figure 1G). The high recurrence obtained implies that phytochemical binding can affect the interactions required in the catalytic region. This metapath of Withanolide R involves Thr26, Leu27, His41, Val42, Cys145, Met165, Leu167, Arg131, Asn133, Thr135 and Asp197. The interaction strength of Thr26 with the phytochemical was maximum followed by Tyr118. Most of these residues were also found to be important in binding to existing promising and potential molecules (Singh et al., 2020). Leu67-Arg76 interaction formed with the highest paths force in PP. The largest interaction strength difference was obtained for Phe66-Leu89 in domain I, Leu268-Val204 in domain 3, and the interaction with high paths force lost in PP was for Leu242-Val247 
(Supplementary material 2 Table 2). Therefore, it can be believed that change in PA's metapath allosteric communications, brought about by these residues, can result in inhibition of the main protease.

MD simulation and Residue Interaction Network (RIN) analysis of the other targets and their complex with phytochemicals

The other targets referred here represents NSP3, NSP9, NSP10 and NSP12. NSP3 is a papain-like proteinase and component of the replication-transcription complexes in SARSCoV-2 (Khan et al., 2021a). The adenosine-5-diphohoribose binding site is where the 27Hydroxywithanolide B was docked (Parida et al., 2021). NSP9 is RNA-binding protein and mediates viral replication (Yoshimoto, 2020). The NSP9 dimerization interface, docked with 27-Hydroxywithanolide B, was used in this work for further analysis (Parida et al., 2021). NSP10 is the cofactor to NSP16 (2'-O-RNA methyltransferase) (Krafcikova et al., 2020). NSP10-NSP16 interface is where the 27-Hydroxywithanolide B bound to the structure (Parida et al., 2021). NSP12 is the RNA dependent RNA polymerase is involved in viral replication (Neogi et al., 2020). Two sited D1: the catalytic site and D2: NSP7 binding interface, docked with 27-Hydroxywithanolide B and Withanolide R respectively, were used in this study (Parida et al., 2021).

\section{Trajectory analysis of the other targets}

The C $\alpha$ RMSD were found to be stable for the other targets (Supplementary Figure 8$10 \mathrm{~A}$ ). In the case of NSP3 and NSP10, the C $\alpha$ RMSF was similar for the free proteins and the complexes with the phytochemicals. For NSP9, the C $\alpha$ RMSF decreased for the phytochemical complex at the C-terminal. For NSP12 the fluctuations decreased at the ligand binding sites.

Analysis of essential dynamics showed that phytochemical binding modulates local protein motions. PCA analysis of these targets (Supplementary Figure 8-9 D, E, 10 D, E, F) showed that N3P explored lesser conformational space compared to N3A, N9P explored lesser conformational space than N9A, N10P explored more conformational space compared to N10A, and N12D1 explored lesser conformational space compared to N12D2 and N12A (Supplementary Figure 8-9 D, E, 10 D, E, F).

Further, to analysis residue contribution to PC1 and PC2, their RMSF were calculated. Loop regions contributed to most variations. It was observed that in PC1, residue fluctuations increased whereas in PC2 space, residue fluctuations decreased in NSP3 (Supplementary 
Figure 8F). Both PC1 and PC2 residue fluctuations decreased for NSP9 at the phytochemical binding site (Supplementary Figure 9F). For NSP10, PC2 residue fluctuations decreased at the ligand binding site (Supplementary Figure 10F). For NSP12, both PC1 and PC2 fluctuation decreased at the phytochemical binding site (Supplementary Figure 11G). The decrease in residue fluctuations shows that the phytochemicals restricted residue movements. DCCM plots reveal that anti-correlated motions increased for $\mathrm{N} 3 \mathrm{P}$ at ligand binding site, correlated motions increased for N9P, N10P, N12D1 and N12D2. Increase in anticorrelated motions in may arise due to ligand binding causing structural perturbation (Henzler-Wildman \& Kern, 2007). Enhancement in correlated motions shows that the phytochemical binding created a more structurally stable environment in the targets.

\section{Free energy landscapes, Structure Network (PSN) and Elastic Network Model-Normal}

\section{Mode Analysis (ENM-NMA) of the other targets}

Analysis of free energy landscapes showed that NSP3 had two low energy bins in the free state, while one at the phytochemical bound state (Supplementary Figure 8 D, E). Free NSP9 had three low energy bins, while the bound state had two such bins (Supplementary Figure 9 D, E). Free NSP10, free and bound form had two minimum energy bins (Supplementary Figure 10 D, E). The free form had much more intermediate states compared to the bound form. NSP12 phytochemical-bound forms explored lesser low energy intermediates compared to the free form (Supplementary Figure 11 D, E, F). FEL revealed $\Delta \mathrm{G}$ value 0 to 15 and $21.4 \mathrm{~kJ} / \mathrm{mol}$ for $\mathrm{N} 3 \mathrm{~A}$ and $\mathrm{N} 3 \mathrm{P}$ respectively. $\Delta \mathrm{G}$ value of 0 to 15.3 and 16.5 were obtained for N3A and N3P respectively. Similarly, $\Delta \mathrm{G}$ value 0 to 17.8 and 17.2 were obtained for N10A and N10P respectively. $\Delta \mathrm{G}$ value 0 to $15.6,16$ and 17.2 were obtained for N12A, N12D1 and N12D2 respectively.

Minimum energy conformers were extracted from these low energy bins and subjected to PSN-ENM-NMA and network centrality analysis. The number of communities increased for N3P and N12D2, no change for N9P and decreased for N10P and N12D1 (Supplementary Figure 8-10 D, E, 11D, E, F). The number of interactions lost, shared, and formed have been presented in Table 2 (Supplementary Data 2). The residues with highest interaction strength with the ligand have also been presented in Table 2. The strongest interacting residues that were absent in the phytochemical-bound form, also have been presented in Table 1. 
Table 1: Linked interactions in the other targets

\begin{tabular}{|l|l|l|l|l|l|}
\hline Target & $\begin{array}{l}\text { Unique } \\
\text { links } \\
\text { free } \\
\text { form }\end{array}$ & $\begin{array}{l}\text { Shared } \\
\text { links }\end{array}$ & $\begin{array}{l}\text { Unique links } \\
\text { phytochemical- } \\
\text { bound form }\end{array}$ & $\begin{array}{l}\text { Residue with } \\
\text { highest path } \\
\text { force with } \\
\text { phytochemical }\end{array}$ & $\begin{array}{l}\text { Linked residues } \\
\text { with highest force } \\
\text { in free form }\end{array}$ \\
\hline NSP3 & 60 & 133 & 47 & Val49, Phe156, & Leu88-Val24 \\
\hline NSP9 & 58 & 83 & 47 & Leu99, Val8 & Arg40-Tyr33 \\
\hline NSP10 & 56 & 72 & 44 & $\begin{array}{l}\text { Leu4345, } \\
\text { Gln4306 }\end{array}$ & Leu4328-Tyr4280 \\
\hline N12D1 & 466 & 570 & 478 & Phe440, Phe437 & Leu498-Val495 \\
\hline N12D2 & 516 & 520 & 468 & Phe843 & Leu498-Val495 \\
\hline
\end{tabular}

Engagement of functionally important residues with the phytochemicals ensures that these phytochemicals can be developed into good inhibitors. In NSP3, residues with highest path force with phytochemical have functional importance. It was reported that V49 hydrogen bonds with the $\alpha$-phosphate and Phe156 also interacts with ADP ribose (Alhammad et al., 2021; Brosey et al., 2021). Similarly, Val8 and Leu99 are involve in dimerization of NSP9 and interacts with Ala108 and Asn97 (PDBID: 6w4b). Interaction strength of residues in the ' $\mathrm{G}^{101} \mathrm{XXXG}^{105}$, motif was also observed to decrease in the phytochemical bound form (Supplementary Data2). Disruption of this motif in SARS-CoV-2 has been reported to reduce RNA binding (Litter et al., 2020). Leu4345 and Gln4306 were reported to form van der Waals interaction with reported plausible inhibitors (Khan et al., 2021b). Phe440, Phe437 and Phe843 were reported to interact with possible inhibitors against NSP12 (Rehman et al., 2020). Specific functional roles of these residues are not clear.

The metapaths of the phytochemicals with the other targets have been illustrated in Supplementary Figure 8-10D, E, 11 D, E, F. The high recurrence metapath with the phytochemical involves residues in NSP3: Val155, Leu126, Leu153, Val151, Val147, Phe166, and Leu122, in NSP9: Asn99 and Leu43, in NSP10: Leu4328 and Ile4352, in NSP12 the residues in the binding pocket were involve in the metapath. 


\section{Analysis of global network properties of the six targets from SARS-CoV-2}

The purpose of this analysis was to see how the number of hubs, linked nodes, shortest paths, links, average path length and length of the longest path, in global network and metapath, changes upon phytochemical binding. Rich literature relating to changes in network properties upon inhibitor binding is unavailable. One study by Fanelli et al. shows the reduction in number of hubs and links upon antagonist binding (Bhattacharyya \& Vishveshwara, 2010; Fanelli et al., 2010;). The global pathway differences showed varying trends among the different SARSCoV-2 targets. The details of the global network properties can be found at Supplementary Table 1- 13. Number of linked nodes showed slight increase or no change for all the targets (Figure 3). The number of links and hubs decreased for all the targets except for spike protein and NSP12D1. The number links in metapath showed decrease for main protease, NSP10, NSP12D1 and NSP12D2. The average path length showed decrease in spike, NSP3, NSP10, N12D1 and N12D2. The length of the longest path showed decrease in spike, NSP10 and N12D1. The number of shortest paths showed decrease in all the targets except for the main protease. The increase in number of shortest paths in main protease can be correlated to increase in average path length of its network (Supplementary Table 3,4). All these suggests phytochemical induced- residue interaction rewiring in the SARS-CoV-2 targets.
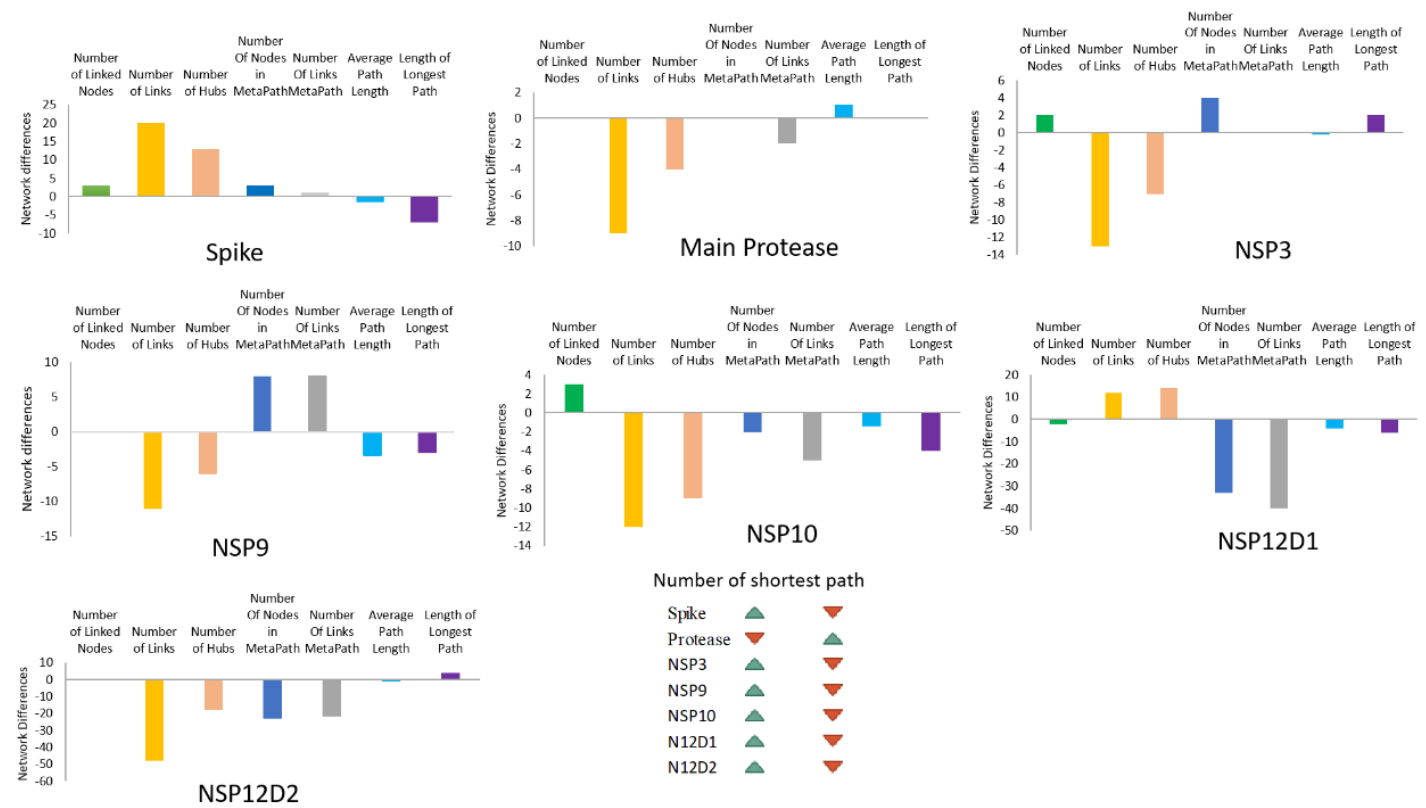

NSP12D1

Figure 3: Difference in global network properties between free-protein and complexes with phytochemical among the SARS-CoV-2 targets. 
The global metapath differences have been illustrated in Supplementary Figure 1-7. The rewiring of the pathway communication upon phytochemical binding, among amino acid residues is clear. In the case of spike protein, the RBD region undergoes rewiring. For example, network connections of Phe456 and Ile402 in SA are altered (Supplementary Figure 1). In the case of main protease complete rewiring in the metapath of the active site, domains II and III were observed (Supplementary Figure 2). Similarly, network rewiring upon phytochemical binding was observed for the other targets (Supplementary Figure 3-7). In the case of NSP3rewiring was observed at the Adenosine-5-Diphosphoribose binding site; in NSP9 at the dimerization interface; in NSP10 at NSP10-NSP16 binding interface; in NSP12D1 at the RNA binding site and in NSP12D2 at the NSP7-NSP12 interface. Conclusively it can be said here that change in residue interaction and rewiring of residue network related to functionally important residues can cause SARS-CoV-2 target inhibition.

\section{Network centrality analysis for the six targets from SARS-CoV-2}

For ease of data integration only the network centrality measure differences for spike and the main protease have been illustrated in Figure 4. The centrality differences of the other targets have been illustrated in Supplementary Figure 11-14. In the case of spike protein, the difference in network centrality measure between SP-SA (Figure 4) showed that the degree centrality and residue interaction strength decreased upon phytochemical binding whereas the betweenness centrality increased for the residues interacting with the phytochemical and in the $\mathrm{N}$-terminal of the RBD region. Significant decrease in interaction strength were observed for residues Leu455-Lys458 and Tyr473. Lys458 and Tyr473 were found to interact with the phytochemical in SP metapath. Significant increase in interaction strength were observed for residues Lys386 with Thr385 in the SP. Betweenness centrality increased for residues Tyr351Trp353, Phe490, Leu492 and Gln493 in SP. These residues were observed to have allosteric communications upon ligand binding as shown in the difference in their global metapath (Supplementary Figure 1) and the filtered metapath for the phytochemical (Figure 1D, E). This also corroborates with the results obtained by PCA and DCCM analysis (Figure 1D, E). 

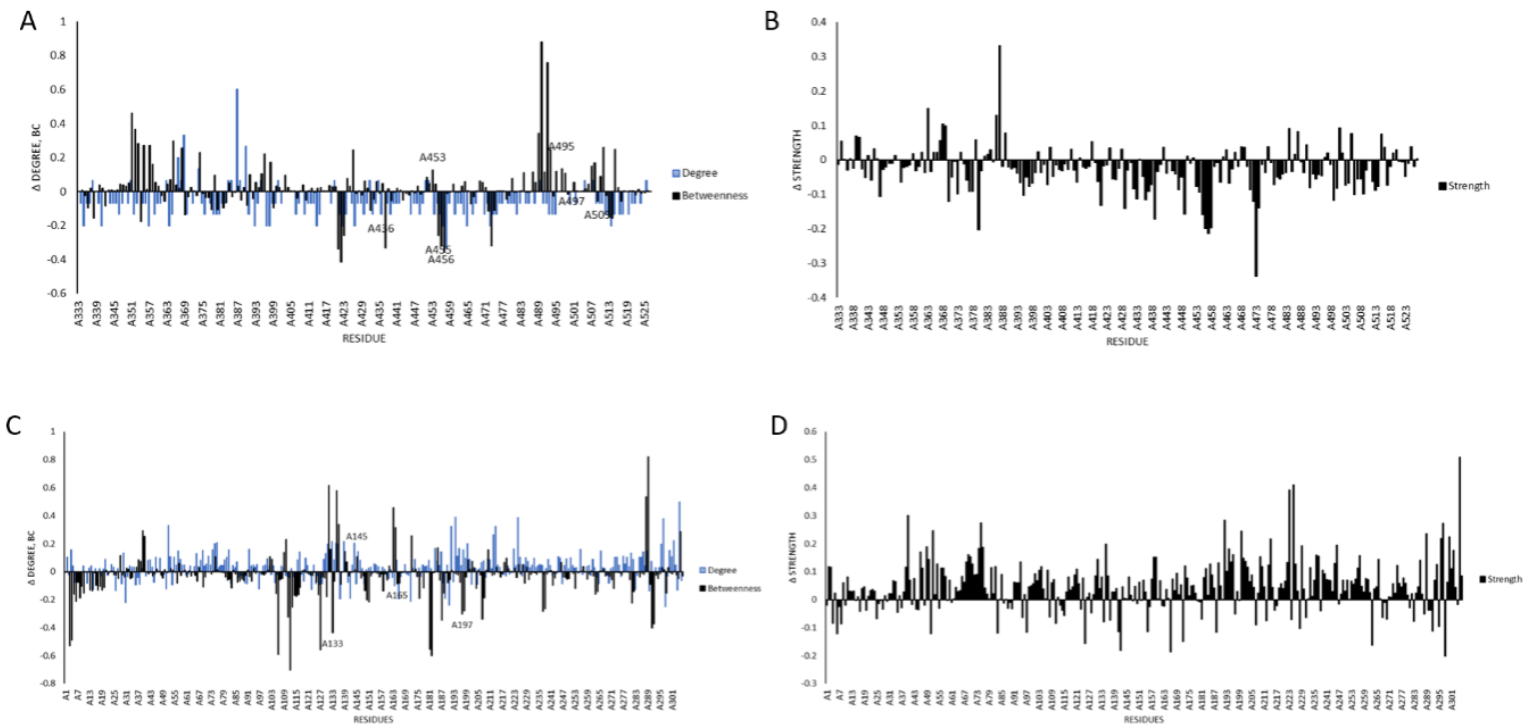

Figure 4: Network centrality analysis of SARS-CoV-2 spike and main protease. A) difference in degree and betweenness centrality between SP and SA (positive values indicate increase in centrality measure for SP). B) Difference in interaction strength in the atom pair network between SP and SA (positive values indicate increase in centrality measure for SP). C) Difference in degree and betweenness centrality between PP and PA (positive values indicate increase in centrality measure for PP). D) Difference in interaction strength in the atom pair network between PP and PA (positive values indicate increase in centrality measure for PP).

In the case of main protease in complex with phytochemical, degree centrality slightly increased for most of the residues. However, the betweenness centrality was observed to have a decreasing trend (Figure $4 \mathrm{C}$ ), especially in the active site region and the loop that connects domain II and domain III of the main protease. Most of the residues also showed increase in interaction strength upon phytochemical binding (Figure $4 \mathrm{D}$ ). The interaction strength significantly decreased for Leu141, Asn142, Glu166, 172, 188in the active site region, in the loop that connects domain II to III, and residues 263, 298 in domain III.

\section{Free energy of binding of phytochemicals with SARS-CoV-2 targets as computed by $M M / P B S A$}

The phytochemicals from Withania somnifera were with the lowest relative binding free energy with the 6 SARS-CoV-2 target sites (Table 2). 27-Hydroxywithanolide B had the lowest relative binding free energy with 3 targets (NSP9, NSP10 and NSP12D1). Withanolide $\mathrm{R}$ had the lowest relative binding free energy with two targets (Main protease and NSP12D2). The best inhibitors for spike and NSP 3 were found to be 2,3-Dihydrowithaferin A and 27Deoxy-14-hydroxywithaferin A. This result interestingly reflects the multi-site binding capability of the phytochemicals. Multi-site binding capacity of natural compounds have been 
reported by Efferth \& Koch (2011), this can increase therapeutic efficiency as SARS-CoV-2 has been reported to have high mutational rates.

Table 2: Relative lowest free binding energy calculated by MM/PBSA

\begin{tabular}{|c|c|c|c|c|c|c|}
\hline $\begin{array}{l}\text { Inhibitor } \\
\text { (PubChem CID) }\end{array}$ & $\begin{array}{l}\text { van der } \\
\text { Waal } \\
\text { energy } \\
(\mathrm{kJ} / \mathrm{Mol})\end{array}$ & $\begin{array}{l}\text { Electrostatic } \\
\text { energy } \\
(\mathbf{k J} / \mathrm{Mol})\end{array}$ & $\begin{array}{l}\text { Polar } \\
\text { solvation } \\
\text { energy } \\
(\mathrm{kJ} / \mathrm{Mol})\end{array}$ & $\begin{array}{l}\text { SASA } \\
\text { energy } \\
(\mathbf{k J} / \mathrm{Mol})\end{array}$ & $\begin{array}{l}\text { Relative } \\
\text { Binding } \\
\text { Free } \\
\text { energy } \\
(\mathrm{kJ} / \mathrm{Mol}) \\
\end{array}$ & $\begin{array}{l}\text { Residue } \\
\text { contribution } \\
\text { Binding } \\
\text { Free energy } \\
(\mathrm{kJ} / \mathrm{Mol})\end{array}$ \\
\hline \multicolumn{7}{|c|}{ Spike (PDB ID: 6lzg) } \\
\hline $\begin{array}{l}\text { 2,3-Dihydrowithaferin A } \\
\text { (15411208) }\end{array}$ & $\begin{array}{l}-219.314 \\
+/- \\
40.940\end{array}$ & $\begin{array}{l}-5.563+/- \\
4.961\end{array}$ & $\begin{array}{l}80.847 \\
+/- \\
18.219\end{array}$ & $\begin{array}{l}-20.822 \\
+/- \\
3.436\end{array}$ & $\begin{array}{l}-164.852 \\
+/- \\
35.403\end{array}$ & $\begin{array}{l}\text { Phe342 } \\
\text { Phe338 } \\
\text { Leu368 } \\
\text { Trp436 }\end{array}$ \\
\hline \multicolumn{7}{|c|}{ Main Protease (PDB ID: 6lu7) } \\
\hline $\begin{array}{l}\text { Withanolide R } \\
\text { (101281364) }\end{array}$ & $\begin{array}{l}-217.460 \\
+/-22.154\end{array}$ & $\begin{array}{ll}-5.388+/- \\
2.422\end{array}$ & $\begin{array}{l}95.300 \\
+/- \\
10.631\end{array}$ & $\begin{array}{l}-19.142 \\
+/- \\
1.304\end{array}$ & $\begin{array}{l}-146.690 \\
+/- \\
18.439\end{array}$ & $\begin{array}{l}\text { MET-165 } \\
\text { LEU-27 } \\
\text { CYS-145 }\end{array}$ \\
\hline \multicolumn{7}{|c|}{ NSP3 (PDB ID: 6w02) } \\
\hline $\begin{array}{l}\text { 27-Deoxy-14- } \\
\text { hydroxywithaferin A } \\
(23266158)\end{array}$ & $\begin{array}{l}-182.278 \\
+/- \\
22.493 \\
\end{array}$ & $\begin{array}{l}-24.154+/- \\
9.225\end{array}$ & $\begin{array}{l}88.830 \\
+/- \\
16.848\end{array}$ & $\begin{array}{l}-18.540 \\
+/- \\
1.882 \\
\end{array}$ & $\begin{array}{l}-136.142 \\
+/- \\
18.419 \\
\end{array}$ & $\begin{array}{l}\text { ILE-131 } \\
\text { PHE-132 }\end{array}$ \\
\hline \multicolumn{7}{|c|}{ NSP9 (PDB ID: 6w4b) } \\
\hline $\begin{array}{l}\text { 27-Hydroxywithanolide } \\
\text { B (44576309) }\end{array}$ & $\begin{array}{l}-126.541 \\
+/- \\
18.008 \\
\end{array}$ & $\begin{array}{l}-4.818+/- \\
3.464\end{array}$ & $\begin{array}{l}41.390 \\
+/- \\
13.171 \\
\end{array}$ & $\begin{array}{l}-12.998 \\
+/- \\
1.474 \\
\end{array}$ & $\begin{array}{l}-102.966 \\
+/- \\
18.012 \\
\end{array}$ & $\begin{array}{l}\text { MET-102 } \\
\text { LEU-98 }\end{array}$ \\
\hline \multicolumn{7}{|c|}{ NSP10 (PDB ID: 6w4h) } \\
\hline $\begin{array}{l}\text { 27-Hydroxywithanolide } \\
\text { B (44576309) }\end{array}$ & $\begin{array}{l}-220.693 \\
+/- \\
29.625 \\
\end{array}$ & $\begin{array}{l}-7.138+/- \\
5.653\end{array}$ & $\begin{array}{l}106.788 \\
+/- \\
18.209 \\
\end{array}$ & $\begin{array}{l}-21.296 \\
+/- \\
1.873 \\
\end{array}$ & $\begin{array}{l}-142.339 \\
+/- \\
27.485 \\
\end{array}$ & $\begin{array}{l}\text { ILE-4308 } \\
\text { LEU-4345 }\end{array}$ \\
\hline \multicolumn{7}{|c|}{ NSP12D1 (PDB ID: 6m71) } \\
\hline $\begin{array}{l}\text { 27-Hydroxywithanolide } \\
\text { B (44576309) }\end{array}$ & $\begin{array}{l}-129.997 \\
+/- \\
14.826 \\
\end{array}$ & $\begin{array}{ll}-2.992 & +/- \\
5.193 & \end{array}$ & $\begin{array}{l}44.279 \\
+/- \\
17.873\end{array}$ & $\begin{array}{l}-12.794 \\
+/- \\
1.516 \\
\end{array}$ & $\begin{array}{l}-101.503 \\
+/- \\
20.820\end{array}$ & $\begin{array}{l}\text { PHE-440 } \\
\text { PHE-415 }\end{array}$ \\
\hline \multicolumn{7}{|c|}{ NSP12D2 (PDB ID: 6m71) } \\
\hline $\begin{array}{l}\text { Withanolide R } \\
\text { (101281364) }\end{array}$ & $\begin{array}{l}-213.228 \\
+/- \\
17.937\end{array}$ & $\begin{array}{l}-11.073+/- \\
3.831\end{array}$ & $\begin{array}{l}97.941 \\
+/- \\
15.457\end{array}$ & $\begin{array}{l}-20.048 \\
+/- \\
1.136\end{array}$ & $\begin{array}{l}-146.409 \\
+/- \\
19.994\end{array}$ & $\begin{array}{l}\text { PHE-843 } \\
\text { ALA-840 }\end{array}$ \\
\hline
\end{tabular}

*The standard error (Std Error) was calculated after 500 step bootstrap analysis. The purchasable chemical compounds have been marked with \#

Residue contribution towards binding free energy led to the observation that the catalytic residue Cys145, Leu 27 (domain I) and Met165 (domain II) of main protease were interacting with Withanolide R with the lowest binding free energy. Leu27 and Met165 has been reported to be important in completing the active site by forming interdomain nonpolar interactions (Suárez \& Díaz, 2020). These residues were also reported multiple times to interact with various published inhibitors (Singh et al., 2020; Suárez \& Díaz, 2020; Mengist et al., 
2021). The residues with lowest binding energy in spike protein were Phe342, Phe338 and Trp436. These residues were observed to interact with various inhibitors identified till date (Kadioglu et al., 2021). In NSP3 the residues reported to interact with (Ile131, Phe132) were with the lowest binding free energy. In NSP9 the dimer interface residues Met102 and Leu98in helix 1 were with the lowest binding free energy with 27-Hydroxywithanolide B. The residues with lowest binding free energy in NSP10 were among the residues known to stimulate methyl transferase activity of NSP 16 (Asn4293-Tyr4349). In NSP 12 D1 (catalytic pocket) and D2 (NSP12-NSP7) binding interface the residues with highest contribution towards relative binding free energy were Phe415, Phe440 and Ala840, Phe843, respectively.

\section{Conclusions}

In this work phytochemicals from Withania somnifera were analysed to be potential inhibitors of a total of six protein targets from SARS-CoV-2. This work shows the application of $1 \mu \mathrm{s}$ all atom MD simulations, protein residue interaction network and network centrality measures to analyse changes in six SARS-CoV-2 targets upon phytochemical binding. MD simulations trajectory analyses showed that the simulations converged, and the systems were stable with the bound phytochemicals with low relative binding free energies calculated by MM/PBSA. From essential dynamics analysis (PCA and DCCM) it could be inferred that conformations dominant in the simulations differed in free and phytochemical-bound SARSCoV-2 targets. Protein structure network analysis revealed changes in community architecture by different number of nodes, hubs and links. Decrease in the number of hubs and links, either in the global pathway or filtered metapath for the phytochemicals, were also observed. Metapath analysis revealed the residues important in allosteric communication with the phytochemicals. Global metapath differences showed that the metapath of free and phytochemical-bound form differed considerably in their network communications and resulted in global network rewiring. The perturbed residue-residue interaction path of functionally important residues due to phytochemical binding were also identified. Network centrality analysis showed that overall degree and betweenness centrality which is related to importance of a residue in a protein network, decreased upon phytochemical binding. Network strength of residues were also observed to alter. Moreover, these phytochemicals were observed to have multipotency- a character required to combat infectious diseases like COVID19 as its protein targets are prone to high mutagenesis rates. Conclusively it can be said that 
phytochemicals from Withania somnifera can be developed into potential SARS-CoV-2 inhibitors.

\section{Acknowledgement}

This work used resources services, and support provided via the COVID-19 HPC Consortium (https://covid19-hpc-consortium.org/), which is a unique private-public effort to bring together government, industry, and academic leaders who are volunteering free compute time and resources in support of COVID-19 research. We would also like to acknowledge Noor Enzymes Private Limited for providing us with the human resources needed to successfully complete this work.

\section{Disclosure statement}

No potential conflict of interest was reported by the authors.

\section{Author contributions statement}

All authors conceived, conducted and analysed the results of experiments equally.

\section{Supplemental online material}

Supplemental data for this article is available online.

\section{ORCID}

Pratap Kumar Parida

Dipak Paul

Debamitra Chakravorty
: https://orcid.org/0000-0002-8193-335X

: https://orcid.org/0000-0002-5664-4601

: https://orcid.org/0000-0002-1520-0780

\section{References}

Alhammad, Y. M., Kashipathy, M. M., Roy, A., Gagné, J. P., McDonald, P., Gao, P., ... \& Fehr, A. R. (2021). The SARS-CoV-2 conserved macrodomain is a mono-ADPribosylhydrolase. Journal of Virology, 95(3), e01969-20. https://doi.org/10.1128/JVI.01969$\underline{20}$

Amitai, G., Shemesh, A., Sitbon, E., Shklar, M., Netanely, D., Venger, I., \& Pietrokovski, S. (2004). Network analysis of protein structures identifies functional residues. Journal of Molecular Biology, 344(4), 1135-1146. https://doi.org/10.1016/j.jmb.2004.10.055 
Amoros, M., Lurton, E., Boustie, J., Girre, L., Sauvager, F., \& Cormier, M. (1994). Comparison of the anti-herpes simplex virus activities of propolis and 3-methyl-but-2-enyl caffeate. Journal of Natural Products, 57(5), 644-647. https://doi.org/10.1021/np50107a013

Bai, Y., Yao, L., Wei, T., Tian, F., Jin, D. Y., Chen, L., \& Wang, M. (2020). Presumed asymptomatic carrier transmission of COVID-19. JAMA, 323(14), 1406-1407. https://doi.org/10.1001/jama.2020.2565

Baker, N. A., Sept, D., Joseph, S., Holst, M. J., \& McCammon, J. A. (2001). Electrostatics of nanosystems: application to microtubules and the ribosome. Proceedings of the National Academy of Sciences, 98(18), 10037-10041. https://doi.org/10.1073/pnas.181342398

Balkrishna, A., Pokhrel, S., Singh, H., Joshi, M., Mulay, V. P., Haldar, S., \& Varshney, A. (2021). Withanone from Withania somnifera attenuates SARS-CoV-2 RBD and host ACE2 interactions to rescue spike protein induced pathologies in humanized zebrafish model. Drug Design, Development and Therapy, 15, 1111-1133. https://doi.org/10.2147/DDDT.S292805

Behloul, N., Baha, S., Guo, Y., Yang, Z., Shi, R., \& Meng, J. (2021). In silico identification of strong binders of the SARS-CoV-2 receptor-binding domain. European Journal of Pharmacology, 890, 173701. https://doi.org/10.1016/j.ejphar.2020.173701

Bhattacharyya, M., \& Vishveshwara, S. (2010). Elucidation of the conformational free energy landscape in H. pylori LuxS and its implications to catalysis. BMC Structural Biology, 10(1), 10, 27. https://doi.org/10.1186/1472-6807-10-27

Brosey, C. A., Houl, J. H., Katsonis, P., Balapiti-Modarage, L. P., Bommagani, S., Arvai, A., ... \& Tainer, J. A. (2021). Targeting SARS-CoV-2 Nsp3 macrodomain structure with insights from human poly (ADP-ribose) glycohydrolase (PARG) structures with inhibitors. Progress in Biophysics and Molecular Biology. https://doi.org/10.1016/j.pbiomolbio.2021.02.002

Cai, Z., Zhang, G., Tang, B., Liu, Y., Fu, X., \& Zhang, X. (2015). Promising anti-influenza properties of active constituent of Withania somnifera ayurvedic herb in targeting neuraminidase of H1N1 influenza: computational study. Cell Biochemistry and Biophysics, 72(3), 727-739. https://doi.org/10.1007/s12013-015-0524-9

Chakrabarty, B., \& Parekh, N. (2016). NAPS: network analysis of protein structures. Nucleic Acids Research, 44(W1), W375-W382. https://doi.org/10.1093/nar/gkw383

Chen, J., \& Shen, B. (2009). Computational analysis of amino acid mutation: a proteome wide perspective. Current Proteomics, 6(4), 228-234. https://doi.org/10.2174/157016409789973734

Chen, Y., Guo, Y., Pan, Y., \& Zhao, Z. J. (2020). Structure analysis of the receptor binding of 2019-nCoV. Biochemical and Biophysical Research Communications, 525(1), 135-140. https://doi.org/10.1016/j.bbrc.2020.02.071

Darden, T., York, D., \& Pedersen, L. (1993). Particle mesh Ewald: An N. $\log (\mathrm{N})$ method for Ewald sums in large systems. The Journal of Chemical Physics, 98(12), 10089-10092. https://doi.org/10.1063/1.464397 
del Sol, A., Fujihashi, H., Amoros, D., \& Nussinov, R. (2006). Residue centrality, functionally important residues, and active site shape: analysis of enzyme and non-enzyme families. Protein Science, 15(9), 2120-2128. https://doi.org/10.1110/ps.062249106

Di Paola, L., De Ruvo, M., Paci, P., Santoni, D., \& Giuliani, A. (2013). Protein contact networks: an emerging paradigm in chemistry. Chemical Reviews, 113(3), 1598-1613. https://doi.org/10.1021/cr3002356

DiMasi, J. A., Grabowski, H. G., \& Hansen, R. W. (2016). Innovation in the pharmaceutical industry: new estimates of R\&D costs. Journal of Health Economics, 47, 20-33. https://doi.org/10.1016/j.jhealeco.2016.01.012

Doniach S., \& Eastman P. (1999). Protein dynamics simulations from nanoseconds to microseconds. Current Opinion in Structural Biology, 9(2), 157-163. https://doi.org/10.1016/S0959-440X(99)80022-0

Dubey K. D., Tiwari R. K., \& Ojha R. P. (2013). Recent advances in protein-ligand interactions: Molecular dynamics simulations and binding free energy. Current ComputerAided Drug Design, 9(4), 518-531. https://doi.org/10.2174/15734099113096660036

Efferth, T., \& Koch, E. (2011). Complex interactions between phytochemicals. The multitarget therapeutic concept of phytotherapy. Current Drug Targets, 12(1), 122-132. https://doi.org/10.2174/138945011793591626

Estrada, E. (2020). Topological analysis of SARS CoV-2 main protease. Chaos, 30(6), 061102. https://doi.org/10.1063/5.0013029

Felline, A., Seeber, M., \& Fanelli, F. (2020). webPSN v2. 0: a webserver to infer fingerprints of structural communication in biomacromolecules. Nucleic Acids Research, 48(W1), W94W103. https://doi.org/10.1093/nar/gkaa397

Ghosh, A., \& Vishveshwara, S. (2007). A study of communication pathways in methionyltRNA synthetase by molecular dynamics simulations and structure network analysis. Proceedings of the National Academy of Sciences, 104(40), 15711-15716. https://doi.org/10.1073/pnas.0704459104

Ghosh, A., \& Vishveshwara, S. (2008). Variations in clique and community patterns in protein structures during allosteric communication: investigation of dynamically equilibrated structures of methionyl tRNA synthetase complexes. Biochemistry, 47(44), 11398-11407. https://doi.org/10.1021/bi8007559

Grant, B. J., Rodrigues, A. P., ElSawy, K. M., McCammon, J. A., \& Caves, L. S. (2006). Bio3d: an R package for the comparative analysis of protein structures. Bioinformatics, 22(21), 26952696. https://doi.org/10.1093/bioinformatics/btl461

Henzler-Wildman, K., \& Kern, D. (2007). Dynamic personalities of proteins. Nature, 450(7172), 964-972. https://doi.org/10.1038/nature06522

Howes, M. J. R., \& Houghton, P. J. (2009) Traditional medicine for memory enhancement. In: Ramawat, K. (Eds) Herbal drugs: ethnomedicine to modern medicine. Springer, Berlin, Heidelberg, pp. 239-291. https://doi.org/10.1007/978-3-540-79116-4_15 
Hu, G., Yan, W., Zhou, J., \& Shen, B. (2014). Residue interaction network analysis of Dronpa and a DNA clamp. Journal of Theoretical Biology, 348, 55-64. https://doi.org/10.1016/j.jtbi.2014.01.023

Huang, Y., Yang, C., Xu, X. F., Xu, W., \& Liu, S. W. (2020). Structural and functional properties of SARS-CoV-2 spike protein: potential antivirus drug development for COVID19. Acta Pharmacologica Sinica, 41(9), 1141-1149. https://doi.org/10.1038/s41401-020-0485$\underline{4}$

Hünenberger, P. H., Mark, A. E., \& Van Gunsteren, W. F. (1995). Fluctuation and crosscorrelation analysis of protein motions observed in nanosecond molecular dynamics simulations. Journal of Molecular $\quad$ Biology, 252(4), $492-503$. https://doi.org/10.1006/jmbi.1995.0514

Huynh, T., Wang, H., \& Luan, B. (2020). In silico exploration of molecular mechanism of clinically oriented drugs for possibly inhibiting SARS-CoV-2's main protease. The Journal of Physical Chemistry Letters, 11(11), 4413-4420. https://doi.org/10.1021/acs.jpclett.0c00994

Islam, M. J., Khan, A. M., Parves, M. R., Hossain, M. N., \& Halim, M. A. (2019). Prediction of deleterious non-synonymous SNPs of human STK11 gene by combining algorithms, molecular docking, and molecular dynamics simulation. Scientific Reports, 9, 16426. https://doi.org/10.1038/s41598-019-52308-0

Jin, Z., Du, X., Xu, Y., Deng, Y., Liu, M., Zhao, Y., ... \& Yang, H. (2020). Structure of M from SARS-CoV-2 and discovery of its inhibitors. Nature, 582(7811), 289-293. https://doi.org/10.1038/s41586-020-2223-y

Joshi, R. S., Jagdale, S. S., Bansode, S. B., Shankar, S. S., Tellis, M. B., Pandya, V. K., Chugh, A., Giri A. P., \& Kulkarni, M. J. (2020). Discovery of potential multi-target-directed ligands by targeting host-specific SARS-CoV-2 structurally conserved main protease. Journal of Biomolecular Structure and Dynamics. https://doi.org/10.1080/07391102.2020.1760137

Kadioglu, O., Saeed, M., Greten, H. J., \& Efferth, T. (2021). Identification of novel compounds against three targets of SARS CoV-2 coronavirus by combined virtual screening and supervised machine learning. Computers in Biology and Medicine, 133, 104359. https://doi.org/10.1016/j.compbiomed.2021.104359

Kaileh, M., Berghe, W. V., Heyerick, A., Horion, J., Piette, J., Libert, C., De Keukeleire, D., Essawi, T., \& Haegeman, G. (2007). Withaferin A strongly elicits IкB kinase $\beta$ hyperphosphorylation concomitant with potent inhibition of its kinase activity. Journal of Biological Chemistry, 282(7), 4253-4264. https://doi.org/10.1074/jbc.M606728200

Khan, M. T., Zeb, M. T., Ahsan, H., Ahmed, A., Ali, A., Akhtar, K., ... \& Irfan, M. (2021b). SARS-CoV-2 nucleocapsid and Nsp3 binding: an in silico study. Archives of Microbiology, 203(1), 59-66. https://doi.org/10.1007/s00203-020-01998-6

Khan, S. A., Zia, K., Ashraf, S., Uddin, R., \& Ul-Haq, Z. (2021a). Identification of chymotrypsin-like protease inhibitors of SARS-CoV-2 via integrated computational approach. Journal of Biomolecular Structure and Dynamics, 39(7), 2607-2616. https://doi.org/10.1080/07391102.2020.1751298 
Klepeis, J. L., Lindorff-Larsen, K., Dror, R. O., \& Shaw, D. E. (2009). Long-timescale molecular dynamics simulations of protein structure and function. Current Opinion in Structural Biology, 19(2), 120-127. https://doi.org/10.1016/j.sbi.2009.03.004

Krafcikova, P., Silhan, J., Nencka, R., \& Boura, E. (2020). Structural analysis of the SARSCoV-2 methyltransferase complex involved in RNA cap creation bound to sinefungin. Nature Communications, 11(1), 1-7. https://doi.org/10.1038/s41467-020-17495-9

Kumar, V., Dhanjal, J. K., Kaul, S. C., Wadhwa, R., \& Sundar, D. (2020). Withanone and caffeic acid phenethyl ester are predicted to interact with main protease $\left(\mathrm{M}^{\mathrm{pro}}\right)$ of SARS-CoV2 and inhibit its activity. Journal of Biomolecular Structure and Dynamics. https://doi.org/10.1080/07391102.2020.1772108

Kumari, R., Kumar, R., Open Source Drug Discovery Consortium, \& Lynn, A. (2014). g_mmpbsa - A GROMACS tool for high-throughput MM-PBSA calculations. Journal of Chemical Information and Modeling, 54(7), 1951-1962. https://doi.org/10.1021/ci500020m

Kwon, M. J., Shin, H. M., Perumalsamy, H., Wang, X., \& Ahn, Y. J. (2020). Antiviral effects and possible mechanisms of action of constituents from Brazilian propolis and related compounds. Journal of Apicultural Research, 59(4), 413-425. https://doi.org/10.1080/00218839.2019.1695715

Lan, J., Ge, J., Yu, J., Shan, S., Zhou, H., Fan, S., ... \& Wang, X. (2020). Structure of the SARS-CoV-2 spike receptor-binding domain bound to the ACE2 receptor. Nature, 581(7807), 215-220. https://doi.org/10.1038/s41586-020-2180-5

Latheef, S. K., Dhama, K., Samad, H. A., Wani, M. Y., Kumar, M. A., Palanivelu, M., Malik, Y. S., Singh, S. D., \& Singh, R. (2017). Immunomodulatory and prophylactic efficacy of herbal extracts against experimentally induced chicken infectious anaemia in chicks: assessing the viral load and cell mediated immunity. VirusDisease, 28, 115-120. https://doi.org/10.1007/s13337-016-0355-3

Lindahl, Abraham, Hess, \& van der Spoel. (2020). GROMACS 2020.2 Source code. Zenodo.

Littler, D. R., Gully, B. S., Colson, R. N., \& Rossjohn, J. (2020). Crystal structure of the SARSCoV-2 non-structural protein 9, Nsp9. iScience, 23(7), 101258. https://doi.org/10.1016/j.isci.2020.101258

Long, Q. X., Liu, B. Z., Deng, H. J., Wu, G. C., Deng, K., Chen, Y. K., ... \& Huang, A. L. (2020). Antibody responses to SARS-CoV-2 in patients with COVID-19. Nature Medicine, 26(6), 845-848. https://doi.org/10.1038/s41591-020-0897-1

Luo, H., Tang, Q. L., Shang, Y. X., Liang, S. B., Yang, M., Robinson, N., \& Liu, J. P. (2020). Can Chinese medicine be used for prevention of corona virus disease 2019 (COVID-19)? A review of historical classics, research evidence and current prevention programs. Chinese Journal of Integrative Medicine, 26(4), 243-250. https://doi.org/10.1007/s11655-020-3192-6

Lyu, S. Y., Rhim, J. Y., \& Park, W. B. (2005). Antiherpetic activities of flavonoids against herpes simplex virus type 1 (HSV-1) and type 2 (HSV-2) in vitro. Archives of Pharmacal Research, 28(11), 1293-1301. https://doi.org/10.1007/BF02978215 
Malik, F., Singh, J., Khajuria, A., Suri, K. A., Satti, N. K., Singh, S., ... \& Qazi, G. N. (2007). A standardized root extract of Withania somnifera and its major constituent withanolide-A elicit humoral and cell-mediated immune responses by up regulation of Th1-dominant polarization in BALB/c mice. Life Sciences, 80(16), 1525-1538. https://doi.org/10.1016/j.lfs.2007.01.029

Martens H., \& Naes T. (1992). Multivariate calibration. John Wiley \& Sons, Inc.

McCammon, J. A. (1984). Protein dynamics. Reports on Progress in Physics, 47(1), 1-46. https://doi.org/10.1088/0034-4885/47/1/001

Mengist, H. M., Mekonnen, D., Mohammed, A., Shi, R., \& Jin, T. (2021). Potency, safety, and pharmacokinetic profiles of potential inhibitors targeting SARS-CoV-2 main protease. Frontiers in Pharmacology, 11, 630500. https://doi.org/10.3389/fphar.2020.630500

Mohan, R., Hammers, H., Bargagna-Mohan, P., Zhan, X., Herbstritt, C., Ruiz, A., Zhang, L., Hanson, A., Conner, B., Rougas, J., \& Pribluda, V. (2004). Withaferin A is a potent inhibitor of angiogenesis. Angiogenesis, 7(2), 115-122. https://doi.org/10.1007/s10456-004-1026-3

Morse, J. S., Lalonde, T., Xu, S., \& Liu, W. R. (2020). Learning from the past: possible urgent prevention and treatment options for severe acute respiratory infections caused by 2019nCoV. ChemBioChem, 21(5), 730-738. https://doi.org/10.1002/cbic.202000047

Munagala, R., Kausar, H., Munjal, C., \& Gupta, R. C. (2011). Withaferin A induces p53dependent freeptosis by repression of HPV oncogenes and upregulation of tumor suppressor proteins in human cervical cancer cells. Carcinogenesis, 32(11), 1697-1705. https://doi.org/10.1093/carcin/bgr192

Neogi, U., Hill, K. J., Ambikan, A. T., Heng, X., Quinn, T. P., Byrareddy, S. N., ... \& Singh, K. (2020). Feasibility of known RNA polymerase inhibitors as anti-SARS-CoV-2 drugs. Pathogens, 9(5), 320. https://doi.org/10.3390/pathogens9050320

Palla, G., Derényi, I., Farkas, I., \& Vicsek, T. (2005). Uncovering the overlapping community structure of complex networks in nature and society. Nature, 435(7043), 814-818. https://doi.org/10.1038/nature03607

Pang, J., Wang, M. X., Ang, I. Y. H., Tan, S. H. X., Lewis, R. F., Chen, J. I. P., ... \& Hsu, L. Y. (2020). Potential rapid diagnostics, vaccine and therapeutics for 2019 novel coronavirus (2019-nCoV): a systematic review. Journal of Clinical Medicine,9(3), 623. https://doi.org/10.3390/jcm9030623

Parida, P. K., Paul, D., \& Chakravorty, D. (2020). The natural way forward: Molecular dynamics simulation analysis of phytochemicals from Indian medicinal plants as potential inhibitors of SARS-CoV-2 targets. Phytotherapy Research,34(12), 3420-3433. https://doi.org/10.1002/ptr.6868

Parida, P. K., Paul, D., \& Chakravorty, D. (2021). Nature's therapy for COVID-19: Targeting the vital non-structural proteins (NSP) from SARS-CoV-2 with phytochemicals from Indian medicinal plants. Phytomedicine

Plus, 1(1),

100002.

https://doi.org/10.1016/j.phyplu.2020.100002 
Rehman, H. M., Mirza, M. U., Ahmad, M. A., Saleem, M., Froeyen, M., Ahmad, S., ... \& Bhinder, M. A. (2020). A putative prophylactic solution for COVID-19: Development of novel multiepitope vaccine candidate against SARS-COV-2 by comprehensive immunoinformatic and molecular modelling approach. Biology, 9(9), 296. https://doi.org/10.3390/biology9090296

RStudio Team (2020). RStudio: Integrated Development for R. RStudio, PBC, Boston, MA. http://www.rstudio.com/

Serkedjieva, J., Manolova, N., \& Bankova, V. (1992). Anti-influenza virus effect of some propolis constituents and their analogues (esters of substituted cinnamic acids). Journal of Natural Products, 55(3), 294-297. https://doi.org/10.1021/np50081a003

Singh, E., Khan, R. J., Jha, R. K., Amera, G. M., Jain, M., Singh, R. P., ... \& Singh, A. K. (2020). A comprehensive review on promising anti-viral therapeutic candidates identified against main protease from SARS-CoV-2 through various computational methods. Journal of Genetic Engineering and Biotechnology, 18(1), 1-12. https://doi.org/10.1186/s43141-020$\underline{00085-\mathrm{Z}}$

Suárez, D., \& Díaz, N. (2020). SARS-CoV-2 main protease: a molecular dynamics study. Journal of Chemical Information and Modeling. 60(12), 5815-5831. https://doi.org/10.1021/acs.jcim.0c00575

Subissi, L., Posthuma, C. C., Collet, A., Zevenhoven-Dobbe, J. C., Gorbalenya, A. E., Decroly, E., ... \& Imbert, I. (2014). One severe acute respiratory syndrome coronavirus protein complex integrates processive RNA polymerase and exonuclease activities. Proceedings of the National Academy of Sciences, 111(37), E3900-E3909. https://doi.org/10.1073/pnas.1323705111

Tandon, N., \& Yadav, S. S. (2020). Safety and clinical effectiveness of Withania somnifera (Linn.) Dunal root in human ailments. Journal of Ethnopharmacology, 255, 112768. https://doi.org/10.1016/j.jep.2020.112768

Tian, X., Li, C., Huang, A., Xia, S., Lu, S., Shi, Z., ... \& Ying, T. (2020). Potent binding of 2019 novel coronavirus spike protein by a SARS coronavirus-specific human monoclonal antibody. Emerging Microbes \& Infections, $9(1), \quad 382-385$. https://doi.org/10.1080/22221751.2020.1729069

Tripathi, M. K., Singh, P., Sharma, S., Singh, T. P., Ethayathulla, A. S., \& Kaur, P. (2020). Identification of bioactive molecule from Withania somnifera (Ashwagandha) as SARS-CoV2 main protease inhibitor. Journal of Biomolecular Structure and Dynamics. https://doi.org/10.1080/07391102.2020.1790425

Wang, Y., Liu, M., \& Gao, J. (2020). Enhanced receptor binding of SARS-CoV-2 through networks of hydrogen-bonding and hydrophobic interactions. Proceedings of the National Academy of Sciences, 117(25), 13967-13974. https://doi.org/10.1073/pnas.2008209117

Wu, C., Liu, Y., Yang, Y., Zhang, P., Zhong, W., Wang, Y., ... \& Li, H. (2020). Analysis of therapeutic targets for SARS-CoV-2 and discovery of potential drugs by computational $\begin{array}{lllll}\text { methods. Acta Pharmaceutica } & \text { Sinica } & \text { B, 10(5), }\end{array}$ https://doi.org/10.1016/j.apsb.2020.02.008 
Xu, X., Chen, P., Wang, J., Feng, J., Zhou, H., Li, X., Zhong, W., \& Hao, P. (2020). Evolution of the novel coronavirus from the ongoing Wuhan outbreak and modeling of its spike protein for risk of human transmission. Science China Life Sciences, 63(3), 457-460. https://doi.org/10.1007/s11427-020-1637-5

Yang, H., Shi, G., \& Dou, Q. P. (2007). The tumor proteasome is a primary target for the natural anticancer compound Withaferin A isolated from "Indian winter cherry". Molecular Pharmacology, 71(2), 426-437. https://doi.org/10.1124/mol.106.030015

Yang, Y., Islam, M. S., Wang, J., Li, Y., \& Chen, X. (2020). Traditional Chinese medicine in the treatment of patients infected with 2019-new coronavirus (SARS-CoV-2): a review and perspective. International Journal of Biological Sciences, 16(10), 1708-1717. https://doi.org/10.7150/ijbs.45538

Yoshimoto, F. K. (2020). The proteins of severe acute respiratory syndrome coronavirus-2 (SARS CoV-2 or n-COV19), the cause of COVID-19. The Protein Journal, 39, 198-216. https://doi.org/10.1007/s10930-020-09901-4

Zandi, K., Teoh, B. T., Sam, S. S., Wong, P. F., Mustafa, M. R., \& AbuBakar, S. (2011). Antiviral activity of four types of bioflavonoid against dengue virus type-2. Virology journal, 8, 560. https://doi.org/10.1186/1743-422X-8-560

Zhang, D. H., Wu, K. L., Zhang, X., Deng, S. Q., \& Peng, B. (2020). In silico screening of Chinese herbal medicines with the potential to directly inhibit 2019 novel coronavirus. Journal of Integrative Medicine, 18(2), 152-158. https://doi.org/10.1016/j.joim.2020.02.005 